\title{
PENGARUH KOMPRES DINGIN TERHADAP PENGURANGAN NYERI LUKA PERINEUM PADA IBU POSTPARTUM DI RSKDIA PERTIWI MAKASSAR 2017
}

\author{
Rismawati \\ Program Studi DIV Bidan Pendidik \\ STIKes Mega Rezky Makassar
}

\begin{abstract}
Abstrak
Penggunaan kompres dingin terbukti dapat menghilangkan nyeri, terapi dingin menimbulkan efek analgetik dengan memperlambat kecepatan hantaran saraf sehingga impuls nyeri yang mencapai otak lebih sedikit. Kompres dingin akan menyebabkan ibu postpartum merasa nyaman, karena efek analgetik dari kompres dingin yang menurunkan kecepatan hantaran syaraf sehingga implus nyeri yang sampai ke otak lebih sedikit sehingga menurunkan sensasi nyeri. Penelitian ini bertujuan untuk mengetahui pengaruh kompres dingin terhadap pengurangan nyeri yang dirasakan pada ibu nifas di RSKDIA Pertiwi Makassar tahun 2017.

Jenis penelitian yang dilakukan adalah "Pre-experimental" yang menggunakan rancangan "One Group Pre Test-Post Test Design". Populasi dalam penelitian ini adalah seluruh ibu nifas yang dirawat di RSKDIA Pertiwi Makassar pada bulan april yaitu sebanyak 66 ibu nifas. Sampel dalam penelitian ini sebanyak 30 responden dengan tekhnik pengambilan sampel yaitu menggunakan Non probability Sampling dengan jenis "Purposive sampling" kemudian data sajikan dengan menggunakan Uji $t$ Sampel Berpasangan dengan melihat Nilai Continuity Correction dengan tingkat kemaknaan $\alpha=0,05$ pada SPSS Versi 16.

Berdasarkan Hasil penelitian yang telah dilakukan hasil analisa dengan uji t diperoleh $\rho=0,000$ sehingga $\rho<\alpha(0,05)$ maka Ho ditolak dan Ha diterima, artinya ada Pengaruh Kompres Dingin Terhadap Pengurangan Nyeri Luka Perineum Pada Ibu Postpartum Di RSKDIA Pertiwi Makassar Tahun 2017. Bagi instansi pelayanan baik rumah sakit maupun puskesmas dapat menfaslitasi bidan untuk menggunakan kompres dingin dalam memberikan asuhan pengurangan nyeri luka perineum.

Kata Kunci : Kompres dingin, Pengurangan nyeri

Daftar Pustaka : :21 Literatur (2005-2016)
\end{abstract}




\begin{abstract}
Cold compress usage proven can lost pain, cold therapy make analgetic effect with making slow down of speed nerve conduction so that impulse of pain to the brain to be less. Cold compress will cause mothers' post partum felt comfortable, because analgetic effect from cold compress that reduce of speed nerve conduction so that pain impulse of pain to the brain to be less so that it can reduce pain.

The purpose of this research was to know the influencing of cold compress towards reducing of perineum wound pain of mothers ' post partum at Pertiwi Regional Women and Children Hospital of Makassar in 2017.

Kind of research applied was pre - experimental research by using one group pre test - post test design. The number of population was all mothers' post partum who cared at Pertiwi Regional Women and Children Hospital of Makassar in April as many as 66 respondents. The number of sample was 30 respondents. Technique of taking sample used non probability sampling with purposive sampling. Then data were analyzed by using sample t test with seeing continuity correlation with $\alpha=0.05$ to SPSS 16 version.

Based on the result of research indicated that t test analysis obtained $\rho=0.000$ so that $\rho<\alpha$ (0.05), HO was rejected and Ha was accepted, it meant that there is influence of cold compress towards reducing of perineum wound pain of mothers ' post partum at Pertiwi Regional Women and Children Hospital of Makassar in 2017. For service office either hospital or public health center can facilitate midwives to use of cold compress in giving reduction of perineum wound pain.
\end{abstract}

Keywords : cold compress, pain reduction

Bibliography : $21(2005-2016)$ 


\section{PENDAHULUAN}

Masa nifas adalah masa sesudah persalinan dan kelahiran bayi, plasenta, serta selaput yang diperlukan untuk memulihkan kembali organ kandungan seperti sebelum hamil dengan waktu kurang lebih 6 minggu (Saleha, 2013).

Nyeri yang dirasakan oleh ibu post partum pada bagian perineum disebabkan oleh luka jahitan pada waktu melahirkan karena adanya jaringan yang terputus. Respon nyeri pada setiap individu adalah unik dan relatif berbeda. Hal ini dipengaruhi antara lain oleh pengalaman, persepsi, maupun sosial kultural individu. Setiap ibu nifas memiliki persepsi dan dugaan yang unik tentang nyeri pada masa nifas, yaitu tentang nyeri dan bagaimana kemampuan mengatasi nyeri. Nyeri yang dirasakan oleh ibu nifas akan berpengaruh terhadap mobilisasi yang dilakukan oleh ibu, pola istirahat, pola makan, pola tidur, suasana hati ibu, kemampuan untuk buang air besar (BAB) atau buang air kecil (BAK), aktivitas sehari-hari, antara lain dalam hal mengurus bayi, mengerjakan pekerjaan rumah tangga, sosialisasi dengan lingkungan dan masyarakat, dan menghambat ketika ibu akan mulai bekerja (Judha, 2012).

Berdasarkan survey awal yang di lakukan peneliti di RSKDIA Pertiwi Makassar tahun 2013, bulan Januari-Desember di dapatkan jumlah ibu bersalin sekitar 3741 orang dan yang mengalami ruptur perineum 1630 orang $(43,57 \%$ ) tahun 2014, bulan Januari-Desember jumlah ibu bersalin sekitar 4555 orang dan yang mengalami ruptur perineum 2122 orang (46,58\%) dan Tahun 2015, bulan JanuariDesember jumlah ibu bersalin sekitar 4681 orang dan yang mengalami ruptur perineum 864 orang $(18,45 \%)$ (Rekam Medik, RSKDIA Pertiwi Makassar).
Berdasarkan data yang diperoleh dari survey yang dilakukan di RSKDIA Pertiwi Makssar manajemen nyeri yang dilakukan bidan yaitu dengan mengajarkan ibu adaptasi terhadap nyerinya dengan tehnik relaksasi dengan menarik nafas panjang menghirup dari hidung dan mengeluarkannya melalui mulut secara perlahan-lahan. Selain dengan metode farmakologis, metode non farmakologis juga merupakan salah satu metode untuk mengurangi rasa nyeri yaitu dengan memberikan kompres dingin dan dianggap efektif dalam menurunkan kasus-kasus nyeri luka perineum pada ibu nifas.

Terkait uraian diatas maka peneliti merasa tertarik untuk mengetahui manfaat pemberian kompres dingin terhadap intensitas nyeri luka perineum pada ibu nifas, sehingga hasil penelitian ini dapat memberikan asuhan kebidanan dengan keluhan nyeri luka perineum sebagai salah satu gerakan sayang ibu.

\section{METODE PENELITIAN}

Jenis penelitian yang digunakan adalah "Preexperimental" yang mencari hubungan sebab akibat antar kompres dingin terhadap penurunan nyeri luka. Penelitian menggunakan intervensi pada satu kelompok sampel dengan dua pengamatan yaitu sebelum dan sesudah perlakaan.

Populasi dalam penelitian ini adalah semua ibu nifas di RSKDIA Pertiwi Makassar pada bulan april yang berjumlah 66 orang.

Sampel adalah bagian dari populasi yang terjangkau yang dapat dipergunakan sebagai subjektif penelitian.

Besar sampel yang berada dalam wilayah kerja dan dilayani di RSKDIA Pertiwi Makassar pada bulan April yang berjumlah 30 orang dengan menggunakan rumus solvin. 
Instrument penelitian menggunakan lembar observasi dan wawancara dengan metode prngukuran nyeri Wong Baker Faces Pain Rating Scale.

Analisa data dengan tehnik analisis univariate untuk memperoleh gambaran dari masing-masing variable dan distribusi frekuensi, sedangkan analisis bivariate dengan menggunakan rancangan "One Group pretest post test" pada uji statistic "Paired Sample t - test". Untuk mengetahui hubungan antara variable independen dan variable dependen. Mengamati sebelum dan sesudah dilakukan kompres dingin pada sampel yang akan dipilih. Menentukan apakah Ho akan diterima atau di tolak dan Ha di terima , dan sebaliknya.

\section{HASIL PENELITIAN}

1. Distribusi frekuensi berdasarkan sebelum perlakuan

Tabel 4.1

Distrbusi frekuensi berdasarkan sebelum perlakuan Ibu Post Partum Di RSKDIA Pertiwi Makassar Tahun 2017

\begin{tabular}{|l|c|c|}
\hline $\begin{array}{c}\text { Tingkatan } \\
\text { nyeri }\end{array}$ & $\begin{array}{c}\text { Frekuensi } \\
(\mathbf{n})\end{array}$ & $\begin{array}{c}\text { Persentase } \\
(\boldsymbol{\%})\end{array}$ \\
\hline Nyeri ringan & 15 & 50,0 \\
\hline Nyeri sedang & 10 & 33,3 \\
\hline Nyeri berat & 5 & 16,7 \\
\hline Jumlah & 30 & 100 \\
\hline
\end{tabular}

Sumber : Data Primer 2017

Berdasarkan tabel 4.1 menunjukkan bahwa dari 30 responden, sebanyak 15 responden $(50 \%)$ nyeri ringan, sebanyak 10 responden $(33,3 \%)$ nyeri sedang, dan sebanyak 5 responden $(16,7 \%)$ nyeri berat.
2. Distribusi frekuensi berdasarkan sesudah perlakuan

Tabel 4.2

Distrbusi frekuensi berdasarkan sesudah perlakuan Ibu Post Partum Di RSKDIA Pertiwi Makassar Tahun 2017

\begin{tabular}{|l|c|c|}
\hline Tingkatan nyeri & $\begin{array}{c}\text { Frekuensi } \\
(\mathbf{n})\end{array}$ & $\begin{array}{c}\text { Persentase } \\
(\boldsymbol{\%})\end{array}$ \\
\hline Tidak nyeri & 0 & 0 \\
\hline Nyeri sangat ringan & 11 & 36,7 \\
\hline Nyeri ringan & 13 & 43,3 \\
\hline Nyeri sedang & 6 & 20,0 \\
\hline Nyeri berat tak & 0 & 0 \\
\hline $\begin{array}{l}\text { Nyeri } \\
\text { tertahankan }\end{array}$ & 30 & 0 \\
\hline Jumlah & 0 & 100 \\
\hline
\end{tabular}

Sumber : Data Primer 2017

Berdasarkan tabel 4.6 menunjukkan bahwa dari 30 responden, sebanyak 11 responden $(36,7 \%)$ nyeri sangat ringan, sebanyak 13 responden $(43,3 \%)$ nyeri ringan, dan sebanyak 6 responden $(20 \%)$ nyeri sedang.

3. Distribusi frekuensi berdasarkan sebelum sesudah perlakuan

Tabel 4.3

Distrbusi frekuensi berdasarkan sebelum dan sesudah perlakuan Ibu Post Partum Di RSKDIA Pertiwi Makassar Tahun 2017

\begin{tabular}{|l|c|c|c|c|}
\hline $\begin{array}{c}\text { Tingkatan } \\
\text { nyeri }\end{array}$ & Sebelum & \% & $\begin{array}{l}\text { sesuda } \\
\text { h }\end{array}$ & \% \\
\hline $\begin{array}{l}\text { Nyeri } \\
\text { sangat } \\
\text { ringan }\end{array}$ & 0 & 0 & 11 & 36,7 \\
\hline
\end{tabular}




\begin{tabular}{|l|c|r|c|c|}
\hline $\begin{array}{l}\text { Nyeri } \\
\text { ringan }\end{array}$ & 15 & $\begin{array}{r}50 \\
, 0\end{array}$ & 13 & 43,3 \\
\hline $\begin{array}{l}\text { Nyeri } \\
\text { sedang }\end{array}$ & 10 & $\begin{array}{r}33 \\
, 3\end{array}$ & 6 & 20,0 \\
\hline $\begin{array}{l}\text { Nyeri } \\
\text { berat }\end{array}$ & 5 & $\begin{array}{r}16 \\
, 7\end{array}$ & 0 & 0 \\
\hline Jumlah & 30 & 100 & 30 & 100 \\
\hline
\end{tabular}

Berdasarkan tabel 4.3 menunjukkan bahwa dari 30 responden, sebanyak $0 \%$ responden yang mengalami nyeri sangat ringan menjadi 11 responden $(36,7 \%)$ setelah kompres dingin, nyeri ringan sebanyak 15 responden $(50,0 \%)$ menjadi 13 responden $(43,3 \%)$, nyeri sedang sebanyak 10 responden $(33,3 \%)$ menjadi 6 responden $(20,0 \%)$, nyeri berat sebanyak 5 responden $(16,7 \%)$ menjaadi 0 responden.

Tabel 4.4. Hasil Uji Normalitas Distribusi Data Pengaruh Kompres Dingin Terhadap Pengurangan Nyeri Luka Perineum.

\begin{tabular}{|l|c|c|c|}
\hline \multicolumn{1}{|c|}{ Perlakuan } & $\boldsymbol{P}$ & $\begin{array}{c}\text { Kolmogrov- } \\
\text { smirnov }\end{array}$ & $\boldsymbol{\alpha}$ \\
\hline $\begin{array}{l}\text { Sebelum } \\
\text { kompres-sesudah } \\
\text { kompres }\end{array}$ & $\mathbf{0 , 0 6 0}$ & $\mathbf{1 , 3 2 6}$ & $\mathbf{0 , 0 5}$ \\
\hline
\end{tabular}

Berdasarkan tabel 4.7 Hasil uji normalitas distribusi data menunjukkan bahwa nilai $P=0,060>$ nilai $\alpha=0,05$ dan nilai kolmogrov-sminorv $=1,326$ maka kesimpulannya data yang diuji mengikuti distribusi normal.
Tabel 4.5 Hasil Uji “Paired Sample $t$ - test” Sebelum dan Sesudah Kompres

\begin{tabular}{|c|c|c|c|c|}
\hline Perlakuan & Mean & $\mathrm{t}$ & $P$ & $\alpha$ \\
\hline $\begin{array}{c}\text { sebelum } \\
\text { kompres } \\
\text { sesudah } \\
\text { komrpes }\end{array}$ & 0.833 & 8.601 & 0.000 & 0,05 \\
\hline
\end{tabular}

Berdasarkan tabel 4.5, hasil output paired sample test diperoleh nilai mean atau rata-rata $=$ 0,833 , nilai thitung $=8,601$ dengan sig (2-tailed) atau nilai $P=0,000$. Nilai ini lebih kecil dari $\alpha=0,05$ $(P=0,000<\alpha=0,05)$, maka $\mathrm{H} 0$ ditolak dan Ha diterima artinya ada pengaruh kompres dingin terhadap pengurangan nyeri luka perineum pada ibu nifas

\section{B. PEMBAHASAN}

\section{Tingkatan Nyeri Luka Perineum Pada Ibu Nifas Sebelum Dilakukan Kompres Dingin}

Menurut Utami (2008), masa nifas dengan luka perineum merupakan pengalaman fisik yang menimbulkan sensasi nyeri. Tingkatan rasa nyeri merupakan subyektif dan sebagian besar setiap ibu akan mengalami, merasakan dan mendeskripsikan nyeri yang berbeda.

Rasa nyeri daerah perineum pada ibu nifas disebabkan oleh adanya robekan pada daerah tersebut pada proses persalinan. Nyeri luka perineum dapat diartikan ketika seorang ibu merasakan nyeri akibat adanya perlukaan pada daerah perineum setelah melalui proses kelahiran bayinya. Rasa nyeri ini dapat terjadi akibat robekan spontan maupun episiotomi pada perineum. Intensitas nyeri yang dirasakan oleh masingmasing individu akan berbeda (Judha, 2012). 


\section{Tingkatan Nyeri Luka Perineum Setelah Diberikan Kompres Dingin}

Teori Potter \& Perry (2006) yang menyatakan bahwa kompres dingin dapat menghilangkan nyeri. Teori ini menyatakan cara kerja dari kompres dingin adalah dengan pelepasan endorphin, sehingga memblok transmisi serabut saraf sensori A-beta yang lebih besar dan lebih cepat. Proses ini menurunkan transmisi nyeri melalui serabut $\mathrm{C}$ dan delta-A berdiameter kecil, sehingga gerbang sinap menutup transmisi impuls nyeri.

Endorphin merupakan substansi seperti morfin yang diproduksi oleh tubuh (termasuk zat kimiawi endogen) dan mempunyai konsentrasi kuat dalam sistem saraf. Endorphin ini berfungsi sebagai inhibitor terhadap transmisi nyeri dengan memblok transmisi impuls otak dan medulla spinalis. Kompres dingin digunakan untuk meredakan nyeri dengan memperlambat kecepatan konduksi saraf, menyebabkan mati rasa dan bekerja sebagai counterirritant. Pemberian tindakan aplikasi dingin dapat menurunkan nyeri dan meningkatkan penyembuhan. Aplikasi dingin berkaitan dengan melambatnya kemampuan sarafsaraf nyeri dalam menyalurkan rangsangan nyeri (Sulistiyani, 2009).

\section{A. KESIMPULAN}

Berdasarkan hasil penelitian pengaruh kompres dingin terhadap pengurangan nyeri luka perineum pada ibu nifas di wilayah kerja RSKDIA Pertiwi

Makassar tahun 2017, maka didapatkan kesimpualan bahwa ada pengaruh kompres dingin terhadap pengurangan nyeri luka perineum

\section{B. SARAN}

1. Bagi tenaga kesehatan khusunya bidan dapat memberikan kompres dingin pada pasien yang mengalami luka perineum dengan senantiasa memperhatikan aspek asuhan sayang ibu.

2. Bagi instansi pelayanan baik rumah sakit maupun puskesmas dapat menfaslitasi bidan untuk menggunakan kompres dingin dalam memberikan asuhan pengurangan nyeri luka perineum.

3. Untuk mencapai hasil yang maksmal dibutuhkan penelitian yang lebih lanjut dengan jumlah sampel yang lebih banyak, waktu penelitian yang lebih lama, serta penambahan variable lain dengan metode yang berbeda.

\section{DAFTAR PUSTAKA}

1. Judha, M, dkk. 2012. Teori Pengukuran Nyeri dan nyeri Persalinan, Nuha Medika, Yokyakarta.

2. Saleha Siti, 2013. Asuhan Kebidanan pada Masa Nifas. Jakarta, Salemba Medika

3. Saleha. (2009). Asuhan Kebidanan Pada Masa Nifas. Jakarta: Salemba Medika

4. Sulistyawati, Ari. 2009. Buku Ajar Asuhan Kebidanan pada Ibu Nifas. Yogyakarta: CV. Andi Offset.

5. Data rekam medikRSKDIA Pertiwi Makassar tahun $2014-2016$ 